\title{
A Mitochondrial Mutant of Coprinus lagopus
}

\author{
By LORNA A. CASSELTON AND AMINA CONDIT \\ Department of Plant Biology and Microbiology, Queen Mary College, \\ Mile End Road, London EI $4 N S$
}

(Received I6 March I972; revised I2 May 1972)

\begin{abstract}
SUMMAR Y
A mutation in Coprinus lagopus, designated acu-Io, led to inability to use acetate as sole carbon source for growth. Using both somatic segregation and non-Mendelian segregation at meiosis as criteria, the mutation was shown to be inherited cytoplasmically. The mutant has a cytochrome spectrum in which the $\alpha$ peak for cytochrome $a$ is absent and a new peak is present when compared to wild-type, corresponding to cytochrome $a_{1}$. Using the $a c u$-Io mutation as a cytoplasmic marker, it has been possible to demonstrate that the migration of nuclei which occurs during dikaryotization takes place independently of any general movement of organelles. It is unlikely, therefore, that nuclear migration is brought about by cytoplasmic streaming.
\end{abstract}

\section{INTRODUCTION}

Mutants with abnormal cytochrome systems are well known in Neurospora crassa (see Gillie, 1970). Like the petite respiratory mutants in the yeast Saccharomyces cerevisiae, many of these Neurospora mutations have been shown to be inherited cytoplasmically, and in terms of recent advances in the study of organelle genetics are thought to have occurred in the mitochondrial DNA. As suggested by Gillie, the Neurospora mutants have intrinsic value for studying mitochondrial genes because they have better defined functional lesions than yeast petites. Mitochondrial mutants are also valuable as cytoplasmic markers in studying nuclear-cytoplasmic relationships.

We describe a mutant in the basidiomycete fungus Coprinus lagopus which has a defective cytochrome system and which shows typical cytoplasmic inheritance. This mutant has been used to demonstrate that there is little or no movement of organelles in conjunction with the active nuclear migration which accompanies the formation of the dikaryon in this basidiomycete.

\section{METHODS}

Strains. H9 $A 6 B 6$ wild-type strain; CC9 $A 6 B 6$ acu-Io obtained from $\mathrm{H} 9$ following treatment with $N$-methyl- $N^{\prime}$-nitro- $N$-nitrosoguanidine; c692 $A_{3} B$ I $a d-3$ obtained from University College London collection.

Culture. Mycelial cultures were incubated at $37^{\circ} \mathrm{C}$. For fruiting, dikaryons were inoculated into bottles containing sterile horse dung and incubated in the light at $26^{\circ} \mathrm{C}$.

Media. Glucose medium was the minimal medium used by Lewis (196I) with the addition of $0.25 \mathrm{~g}$ magnesium sulphate/l (Casselton \& Casselton, I966). This was supplemented when necessary with $100 \mathrm{mg}$ adenine sulphate/1. The acetate medium contained the following/ distilled water: sodium acetate, $10 \mathrm{~g}$; ammonium tartrate, $5.0 \mathrm{~g}$; potassium dihydrogen orthophosphate, $\mathrm{r} \cdot 0 \mathrm{~g}$; disodium hydrogen orthophosphate, $2 \cdot 25 \mathrm{~g}$; thiamine, $40 \mu \mathrm{g}$; magnesium sulphate, $0.25 \mathrm{~g}$. 
Techniques. General techniques for using Coprinus have been described by Lewis (1961) and more recently by Anderson (I97I). The veil cell technique was devised by Cowan (1964).

Cytochrome spectra. Mycelium was grown by inoculating oidial suspensions into $200 \mathrm{ml}$ liquid glucose medium in $500 \mathrm{ml}$ Erlenmeyer flasks. These were placed on a reciprocal shaker in a water bath maintained at $37^{\circ} \mathrm{C}$ until sufficient growth was obtained ( 5 to 7 days). The mycelial pellets were harvested by filtering through muslin, washed and then packed into a IO $\times$ IO $\mathrm{mm}$ quartz cuvette. The spectrum of reduced cytochromes was prepared without further treatment by scanning in a Pye-Unicam SP 800 u.v. recording spectrophotometer, using damp muslin as blank.

\section{RESULTS}

The mutant strain CC9 was isolated during selection for mutations affecting acetate metabolism. The mutant grows slowly on glucose medium and so poorly on acetate medium as to be classified as acetate non-utilizing. The mutation has been designated $a c u$-IO. The mutant phenotype failed to segregate in a routine cross to wild-type, indicating that the mutation might be cytoplasmic, and this, together with inability to grow on acetate as sole carbon source, suggested a possible mitochondrial defect. Experiments were therefore designed firstly to confirm the cytoplasmic inheritance of the mutation, and secondly to see if the mutation affected the cytochrome spectrum.

Reciprocal dikaryons. The criteria which can be used to identify a cytoplasmic mutation have been described by Jinks (1964); which of these can be used depends largely on the organism. Somatic segregation and non-Mendelian segregation at meiosis have been most applicable to Coprinus. Both tests require the formation of a dikaryon between $\mathrm{CC} 9$ and another compatible monokaryon. We have used the strain $\mathrm{C} 692$ which carries the $a d-3$ gene mutation causing a growth requirement for adenine. This has provided a readily identifiable nuclear gene marker for differentiating the two nuclei in somatic segregants from the dikaryon, and a control of normal nuclear gene segregation at meiosis.

Reciprocal crosses of the type used in studies with Neurospora are not possible in a basidiomycete such as Coprinus because there is no differentiation of sex organs; plasmogamy occurs between vegetative hyphae. However, after anastomosis between hyphae of compatible monokaryons there is generally a reciprocal exchange of nuclei which then migrate through the established monokaryotic hyphae to set up the binucleate celled dikaryon on which fruit bodies are formed. Dikaryotic hyphae emerge around the periphery of the two mated monokaryons and can readily be distinguished by regular clamp connections at all septa. It is thus possible to recover reciprocally constituted dikaryons with respect to the donor nucleus and the recipient mycelium. It has been assumed that the recipient mycelium provides the majority of the cytoplasm (Day, I959). If the $a c u$-Io mutation is cytoplasmic, we can put this assumption to the test. If true, we would expect to obtain two reciprocal dikaryons which are phenotypically distinguishable by their ability to grow on acetate.

Monokaryons were mated on glucose medium and dikaryotic hyphae were subcultured to fresh glucose medium before testing for ability to grow on acetate. When the mutant CC9 was the recipient strain, the dikaryon failed to grow at all on acetate medium, but when C692 was the recipient, the dikaryon grew well on this medium. Since the nuclear composition of the two dikaryons was identical, it can be concluded, in this case, that inability to grow on acetate is determined by the cytoplasm. The reciprocal dikaryons were also distinguishable on glucose medium; the growth of the $a c u^{+}$dikaryon being faster and more vigorous than that of the mutant dikaryon. Fig. I illustrates the appearance of the dikaryotic mycelium produced on mating $\mathrm{CC} 9$ and $\mathrm{C692}$. The reciprocal dikaryons are clearly distin- 


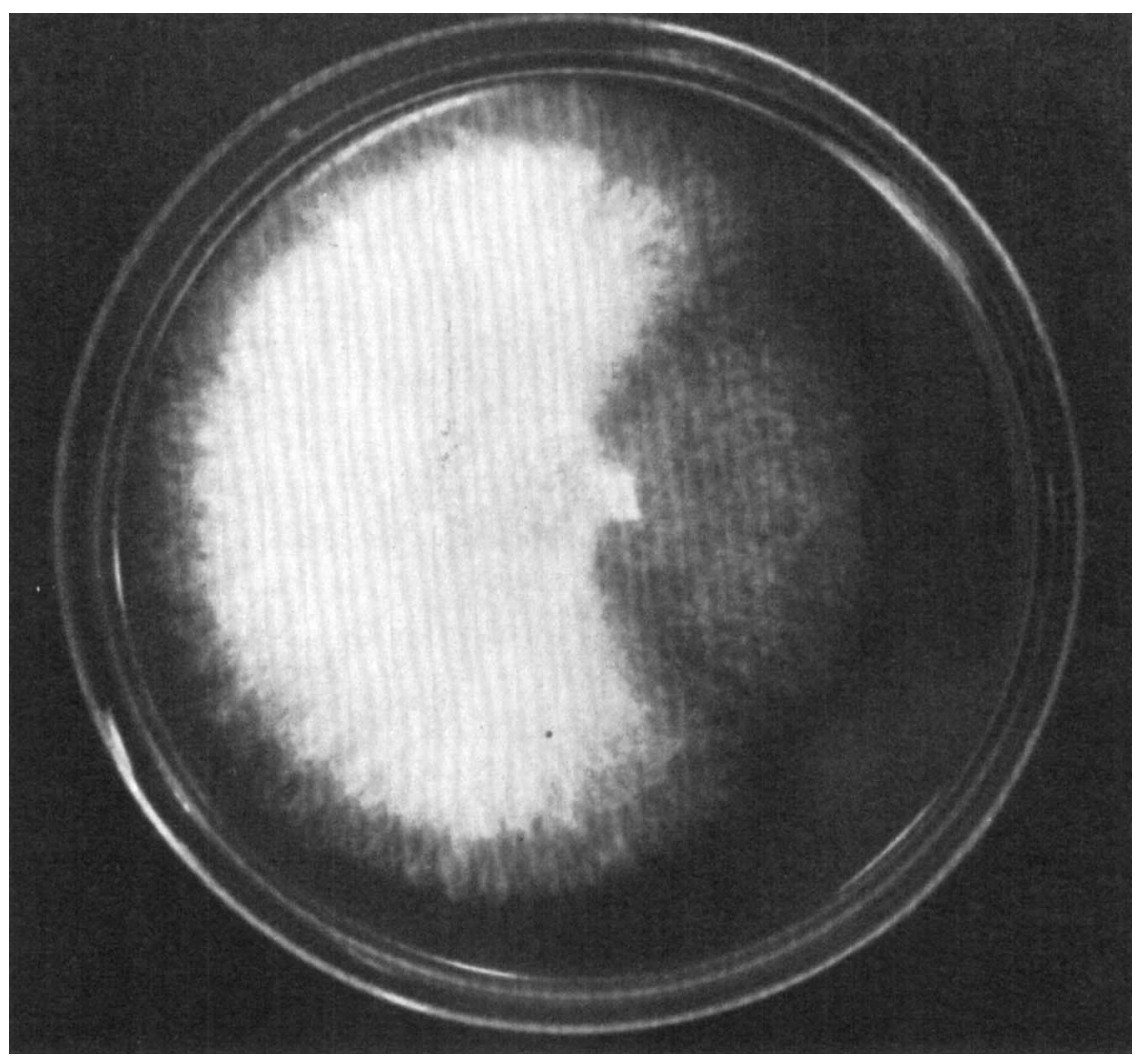

Fig. I. Reciprocally formed dikaryons from a mating between $\mathrm{C} 692\left(\mathrm{acu}^{+}\right)$and the mutant strain $\mathrm{CC} 9$ $(a c u-10)$. In the centre are the two original monokaryotic inocula placed $\mathrm{I} \mathrm{cm}$ apart; $\mathrm{CC} 9$ on the right and 6992 on the left. The dikaryotic mycelium appears divided into two discrete sectors. The fluffy fast growing mycelium on the left has the $a c u^{+}$cytoplasm whereas the sparse slow growing mycelium on the right has the $a c u$-1o cytoplasm.

guishable as two discrete sectors. The clear phenotyptic difference between the reciprocal dikaryons provides the first real evidence that the nuclear donor strain does not donate cytoplasmic components as well. From a mycological point of view, this is of particular interest with regard to the mechanism of nuclear migration in fungi, and will be discussed later.

The heterokaryon test (somatic segregation). The heterokaryon test (Jinks, I964) will show that a cytoplasmically determined character can segregate somatically with either of the two nuclear types introduced into a heterokaryon. In Coprinus this test can be applied by making a dikaryon between the cytoplasmic mutant and another strain, and then resolving the dikaryon into monokaryons of either nuclear type. Resolution can be made at any time before meiosis, either from the vegetative mycelium by the chlamydospore technique (Lewis, 196I), or later from the veil cells which cover the pileus of the fruit body (Cowan, 1964). Both the reciprocal dikaryons have been resolved by these two techniques (see Table I).

Four phenotypes are possible in the monokaryotic resolvates with respect to the two nuclei, distinguished by the $a d-3$ alleles, segregating independently of the cytoplasmically determined $a c u$-Io alleles. 
Table I. Somatic segregants obtained by resolving reciprocal dikaryons

\begin{tabular}{|c|c|c|c|c|c|}
\hline & & \multicolumn{4}{|c|}{ Possible segregants } \\
\hline \multicolumn{2}{|c|}{ Dikaryon } & \multicolumn{2}{|c|}{ Parental } & \multicolumn{2}{|c|}{ Recombinant } \\
\hline Recipient strain & Donor strain & $a d-3 a c u^{+}$ & $a d^{+} a c u-10$ & ad-3 acu-Io & $a d^{+} a c u^{+}$ \\
\hline \multicolumn{6}{|c|}{ (a) Chlamydospore resolvates } \\
\hline $\begin{array}{l}a d-3 a c u^{+}(\mathrm{c692}) \\
a d^{+} a c u-10(\mathrm{cc} 9)\end{array}$ & $\begin{array}{l}a d^{+} a c u-\mathrm{IO}(\mathrm{CC} 9) \\
a d-3 a c u^{+}(\mathrm{c} 692)\end{array}$ & $\begin{array}{l}7 \\
0\end{array}$ & $\begin{array}{r}0 \\
67\end{array}$ & $\begin{array}{r}0 \\
13\end{array}$ & $\begin{array}{r}71 \\
0\end{array}$ \\
\hline \multicolumn{6}{|c|}{ (b) Veil cell resolvates } \\
\hline$a d-3 a c u^{+}(\mathrm{c} 692)$ & $a d^{+} a c u-10(\mathrm{cc} 9)$ & 16 & o & o & 37 \\
\hline$a d^{+} a c u-10$ (CC9) & $a d-3 a c u^{+}(\mathrm{c} 692)$ & 38 & 0 & 0 & 35 \\
\hline
\end{tabular}

Table 2. Analysis of basidiospore progeny from fruit bodies produced on reciprocal dikaryons

\begin{tabular}{|c|c|c|c|c|c|c|c|}
\hline \multicolumn{2}{|c|}{ Dikaryon } & \multirow{2}{*}{$\begin{array}{l}\text { Normal } \\
\text { tetrads } \\
(\%)\end{array}$} & \multirow{2}{*}{$\begin{array}{c}\text { Viable } \\
\text { spores } \\
(\%)\end{array}$} & \multirow{2}{*}{\multicolumn{2}{|c|}{$\begin{array}{l}\text { Nuclear gene } \\
a d^{+}: a d-3\end{array}$}} & \multirow{2}{*}{\multicolumn{2}{|c|}{$\begin{array}{c}\text { Cytoplasmic gen } \\
a c u^{+}: a c u \text {-IO }\end{array}$}} \\
\hline Recipient strain & Donor strain & & & & & & \\
\hline $\begin{array}{l}a d-3 a c u^{+}(\mathrm{c692}) \\
a d^{+} a c u-10(\mathrm{cc9})\end{array}$ & $\begin{array}{l}a d^{+} a c u-10(\mathrm{cc} 9) \\
a d-3 a c u^{+}(\mathrm{c} 692)\end{array}$ & $\begin{array}{l}96 \cdot 7 \\
98 \cdot 0\end{array}$ & $\begin{array}{l}96 \cdot 5 \\
93 \cdot 0\end{array}$ & $\begin{array}{l}53 \\
49\end{array}$ & $\begin{array}{l}57 \\
53\end{array}$ & $\begin{array}{l}110 \\
102\end{array}$ & $\begin{array}{l}0 \\
0\end{array}$ \\
\hline
\end{tabular}

The phenotypes of the chlamydospore resolvates (Table I $a$ ) confirms the conclusions as regards the dikaryotic mycelium, that the cytoplasmic phenotype is exclusively that of the recipient mycelium. Thus when $\mathrm{CC} 9$ is the recipient, both nuclear types were recovered with $a c u$-Io but not $a c u^{+}$. Conversely, when $\mathrm{C692}$ was the recipient, both nuclear types were recovered with $\mathrm{acu}^{+}$but not $a c u$-IO. In both analyses, however, one parental and one recombinant phenotype was obtained, clearly demonstrating somatic segregation of the acetate phenotypes.

The veil cell resolvates also show somatic segregation (Table $\mathrm{I} b$ ). However, they are interesting for another reason. In contrast to resolvates obtained from chlamydospores, those obtained from veil cells of either reciprocal dikaryon were $a c u^{+}$. This follows from the finding that normal fruit body development is dependent on the $a c u^{+}$phenotype. Mature fruit bodies were produced on the initially $a c u^{+}$dikaryon within the usual Io-day period, but took 3 weeks on the reciprocal $a c u$-Io dikaryon. When a vegetative culture was made from stipe cells of a fruit body on this latter dikaryon it was found to be $a c u^{+}$. Complete conversion of the $a c u$-Io dikaryon to $a c u^{+}$is evident from the veil cell resolvates themselves, which are $a c u^{+}$independent of the nuclear type. The $a c u^{+}$phenotype cannot therefore be due to a suppressor gene mutation in one of the nuclei. This is confirmed by analysis of a sample of basidiospore progeny from this fruit body.

Non-Mendelian segregation. Analysis of samples of basidiospore progeny derived from each of the fruit bodies from which veil cells were removed are presented in Table 2. In each of the samples there is the expected I:I Mendelian segregation for the two alleles of the nuclear gene $a d-3$. There is, however, no segregation of the $a c u$-Io cytoplasmic mutation. Non-segregation of $a c u$-Io cannot be attributed to any irregularity at meiosis since, as also shown in Table 2, tetrad production was normal and basidiospore viability nearly $100 \%$. In the case of the formerly $a c u^{-}$dikaryon, non-recovery of $a c u$-Io in the basidiospore progeny indicates a real loss of the mutation as was apparent in veil cell segregants. There is no evidence of a nuclear suppressor gene mutation of the type described for comparable 


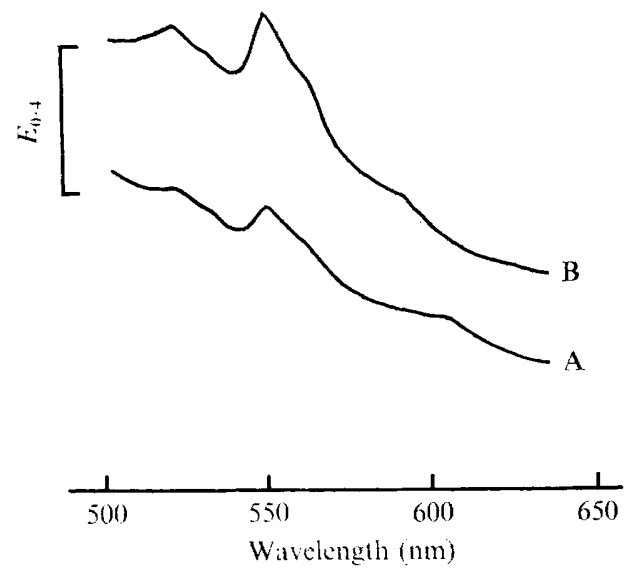

Fig. 2. Cytochrome spectra of mycelia of a wild-type strain H9 (A) and of the mutant strain CC9 carrying the $a c u$-Io mutation (B). $\propto$ Peaks of cytochromes $a, b$ and $c$ occur at the wavelengths 600 , 560 and $550 \mathrm{~nm}$ respectively. The peak at $590 \mathrm{~nm}$ corresponds to cytochrome $a_{1}$. $\beta$ Peaks of cytochromes $b$ and $c$ occur at 532 and $52 \mathrm{I} \mathrm{nm}$.

Neurospora mutants (Mitchell \& Mitchell, I956; Gillie, I970). The fact that acu-Io fails to segregate at meiosis illustrates non-Mendelian segregation.

Reversion of acu-IO. From the mutant cytochrome spectrum described below, together with cytoplasmic inheritance, it seems likely that the $a c u$-Io mutation is in the mitochondrion. The origin of normal mitochondria in the previously mutant dikaryon cannot, unfortunately, be determined in the present experiments. A few normal non-mutant mitochondria may have been derived from the nuclear donor strain, but there was no evidence of this in the sample of chlamydospores analysed. Alternatively, they may have arisen by reversion of the mutation in a few organelles. To test this latter possibility, asexual spores (oidia) from the original mutant strain CC9 were sown on acetate medium to test for reversion to $\mathrm{acu}^{+} . \mathrm{acu}^{+}$ colonies were obtained at the relatively high frequency of $\mathrm{I}$ in $\mathrm{IO}^{4}$ viable spores. Reversion would therefore seem a very likely source of normal mitochondria, but it would require additional organelle markers to be certain.

Cytochrome spectra. Based on the absorption spectra observed, Mitchell, Mitchell \& Tissières (1953) distinguished two different patterns of cytochrome defects caused by cytoplasmic mutations in Neurospora. As a result of the mi-I mutation, usually called poky, there is apparently a complete elimination of both cytochromes $a$ and $b$, and greatly elevated amounts of cytochrome $c$. The mi-3 mutation leads to loss of cytochrome $a$; but cytochrome $b$ is still present together with excess cytochrome $c$. More recent studies have confirmed these findings (Griffiths, Bertrand \& Pittenger, I968). Moreover, Griffiths et al. (I968) found that a variety of independently isolated cytoplasmic mutants of Neurospora, all having cytochrome defects, could be subdivided into two groups with respect to whether their cytochrome spectrum was identical to that of poky or of $m i-3$.

In Fig. 2 are the absorption spectra obtained for the CC9 mutant in Coprinus, together with that for the wild-type strain H9. It is apparent that $a c u$-Io results in an $m i-3$ type spectrum. Considering the $\alpha$ peaks, there is apparently no cytochrome $a(600 \mathrm{~nm})$ but cytochrome $b$ is still present $(560 \mathrm{~nm})$. By comparison with the spectrum obtained for the wild-type strain, the $\alpha$ peak for cytochrome $c\left(55^{\circ} \mathrm{nm}\right)$ is much better defined, indicating enhanced levels of this cytochrome. An interesting feature of the CC9 spectrum is the peak at $590 \mathrm{~nm}$ which corresponds to that of cytochrome $a_{1}$. Mitchell et al. (1953) reported the presence of 
cytochrome $a_{1}$ in $m i-3$ although Griffiths et al. (1968) failed to find it in their more recent study. We have looked at the CC9 spectrum on four separate occasions, and each time found this peak at $590 \mathrm{~nm}$.

The cytochrome spectra of three strains derived during the experiments described were also examined. One strain was a somatic veil cell segregant having the $\mathrm{CC} 9$ nucleus but the $\mathrm{acu}^{+}$ phenotype. The other two strains were $a c u^{+}$revertants obtained directly from CC9. In all cases the spectra were comparable to that of the wild-type strain.

\section{DISCUSSION}

The acu-Io mutation in Coprinus lagopus has been shown to be associated with an abnormal cytochrome system in the mitochondria and to be inherited cytoplasmically. By analogy with comparable mutants of Neurospora crassa and yeast, it seems likely that the acu-Io mutation is in the mitochondrial DNA. The fact that the mutation appears to back mutate readily suggests that it is unlikely to involve more than a single base change.

The cytochrome spectrum of the $a c u$-ro mutant strain is very similar to that caused by the mi-3 cytoplasmic mutation in Neurospora crassa (Mitchell et al. 1956). Like another cytoplasmic mutation, poky, $m i-3$ has a pleiotropic effect on the respiratory mechanism. The primary effects of these mutations, however, are not known. The claim by Woodward $\&$ Munkres (I966) that both poky and $m i-3$ lead to single amino acid substitutions in the mitochondrial structural protein has recently been discounted by Zollinger \& Woodward (1972). Zollinger \& Woodward consider the possibility that the many defects associated with poky could be caused by transcription errors in the mitochondrial protein-synthesizing system.

The identification of a mitochondrial mutation in Coprinus lagopus has provided a valuable cytoplasmic marker for examining the interesting process of dikaryotization. The formation of the secondary mycelium, or dikaryon, in a basidiomycete such as $C$. lagopus involves extensive migration of nuclei donated by one monokaryon through the established hyphae of another. Characteristic of basidiomycete hyphae are the complex dolipore septa between each cell which normally form a barrier to nuclear movement (Girbardt, I96I; Moore \& McAlear, 1962). When nuclear migration is occurring in a monokaryon, these complex dolipore septa are disrupted to give simple septa through which nuclei may pass easily (Giesy \& Day, 1965). Once established, the dikaryon has dolipore septa and nuclear migration is restricted to the clamp connexions.

Little is known about the mechanism of nuclear migration in fungi, and it is often assumed that the nuclei are carried passively by cytoplasmic streaming (Burnett, 1968). If this were so, disruption of the monokaryotic dolipore septa during dikaryotization would remove any barrier to general cytoplasmic movement and one might expect organelles to pass from the donor into the recipient mycelium along with the nuclei. However, by direct microscopic observation of nuclear migration in another basidiomycete, Schizophyllum commune, Niederpruem (1969) found no evidence of cytoplasmic streaming or obvious organelle movement. We now provide genetic evidence to support Niederpruem's observations. Using the $a c u$-Io mutation as a cytoplasmic marker, we find that the dikaryotic mycelium which grows out from the periphery of the mated monokaryons has exclusively the cytoplasmic phenotype of the recipient mycelium. The maintenance of two discrete reciprocal dikaryons is very clearly illustrated in Fig. I, where the phenotypic difference imposed by different cytoplasms is apparent. Thus few, if any, mitochondria migrate with the donor nuclei. This would be unlikely if cytoplasmic streaming were a means of effecting nuclear migration in this fungus. 
Whilst the vegetative dikaryotic mycelium can grow with defective mitochondria, it requires the presence of normal mitochondria before the large mushroom fruit bodies can develop properly. Whatever the origin of the normal mitochondria in the previously mutant dikaryon, the mitochondrial population must have changed rapidly in response to the selective pressure of fruiting requirements.

We wish to thank Mr R. Lucibell and Mr A. Valdemar for technical assistance. This work was assisted by a grant from the Science Research Council (to L.A.C.) which is gratefully acknowledged.

\section{REFERENCES}

Anderson, G. E. (1971). The Life History and Genetics of Coprinus lagopus. Weston-super-Mare, Somerset: Harris Biological Supplies Ltd.

Burnett, J. H. (1968). Fundamentals of Mycology. London: Edward Arnold.

Casselton, L. A. \& CAsSelton, P. J. (1966). The control of fruiting of Coprinus lagopus on certain synthetic media. Transactions of the British Mycological Society 49, 579-58I.

Cowan, J. W. (I964). Recovery of monokaryons from veil cells of fruit bodies of Coprinus lagopus sensu Buller. Nature, London 204, I I I 3-1 II4.

DAY, P. R. (1959). A cytoplasmically controlled abnormality of the tetrads of Coprinus lagopus. Heredity $\mathbf{1 3}$, $8 \mathrm{I}-87$.

Giesy, R. M. \& Day, P. R. (I965). The septal pores of Coprinus lagopus (Fr.) sensu Buller in relation to nuclear migration. American Journal of Botany 52, 287-293.

GILLIE, O. J. (1970). Methods for the study of nuclear and cytoplasmic variation in respiratory activity of Neurospora crassa, and the discovery of three new genes. Journal of General Microbiology 6r, 379-395.

GirbardT, M. (1961). Licht- und elektronmikroskopische Untersuchungen an Polystictus versicolor. II. Die Feinstruktur von Grundplasma und Mitochondrien. Archiv für Mikrobiologie 39, 35I-359.

Griffiths, A. J. F., Bertrand, H. \& Pittenger, T. H. (I968). Cytochrome spectra of cytoplasmic mutants in Neurospora. Neurospora Newsletter 13, 16-17.

JINKs, J. L. (1964). Extrachromosomal Inheritance. Englewood Cliffs, New Jersey: Prentice-Hall, Inc.

LewIS, D. (196I). Genetic analysis of methionine suppressors in Coprinus. Genetical Research 2, I4I-I55.

Mitchell, M. B. \& Mitchell, H. K. (1956). A nuclear gene suppressor of a cytoplasmically inherited character in Neurospora crassa. Journal of General Microbiology 14, 84-89.

Mitchell, M. B., Mrtchell, H. K. \& Tissières, A. (1953). Mendelian and non-Mendelian factors affecting the cytochrome system in Neurospora crassa. Proceedings of the National Academy of Sciences of the United States of America 39, 606-613.

Moore, R. T. \& MCAlear, J. H. (1962). Fine structure of Mycota. 7. Observations on septa of Ascomycetes and Badidiomycetes. American Journal of Botany 49, 86-94.

Niederpruem, D. J. (1969). Direct studies of nuclear movements in Schizophyllum commune. Archiv für Mikrobiologie 64, 387-395.

WOODWARD, D. O. \& MUNKRES, K. D. (1966). Alterations of maternally inherited mitochondrial structural protein in respiratory deficient strains of Neurospora. Proceedings of the National Academy of Sciences of the United States of America 55, 872-880.

ZOLLINGER, W. D. \& WOODWARD, D. O. (1972). Comparison of cysteine and tryptophan content of insoluble proteins derived from wild-type and mi-I strains of Neurospora crassa. Journal of Bacteriology 109, I00IIOI3. 